\title{
Dogs in Learning: Transforming Education
}

\section{Christina Birbil $^{1}$, Theo Koutsopoulos ${ }^{1}$, Cathy Makropoulos ${ }^{1}$, Alessandra Sax ${ }^{1}$, Stefanos Gialamas $^{1}$, Konstantinos Koutsopoulos ${ }^{2}$}

${ }^{1}$ American Community Schools of Athens, Athens ,Greece

${ }^{2}$ School of Architecture, National Technical University of Athens, Athens, Greece

Email address:

gialamas@acs.gr (S. Gialamas)

\section{To cite this article:}

Christina Birbil, Theo Koutsopoulos, Cathy Makropoulos, Alessandra Sax, Stefanos Gialamas, Konstantinos Koutsopoulos. Dogs in Learning: Transforming Education. International Journal of Elementary Education. Vol. 4, No. 2, 2015, pp. 16-24. doi: 10.11648/j.ijeedu.20150402.11

\begin{abstract}
Every academic institution is clearly obliged to have great aspirations for its students. In addition since the world has changed exponentially in ways that are not always easy to understand, so as to accurately predict, and prepare students for the future, a new trajectory in education is urgently needed. ACS Athens has developed and is implementing for the past 8 years a new educational paradigm called the Global Morfosis Paradigm, an authentic, unbounded, and exciting educational paradigm educating students for complex and ambiguous future needs. In particular, students in primary grades, learn in an environment of engagement with creativity and innovation, which should be the norm and not the exception. The program Dogs in Learning (DiL) is designed to use highly trained dogs as an inspirational vehicle to help children understand and apply everyday issues related to human behavior such as: leadership, non-violence, patience, respect, kindness, love, team work, responsibility, confidence, friendship, trust, empathy, etc. In addition a plethora of curriculum contents at the Elementary School are being taught and learned by students in a meaningful and fun way utilizing well trained dogs under the guidance and leadership of teachers.
\end{abstract}

Keywords: Dogs, Learning, Morfosis, Elementary School, Innovation, Leadership, Psychology, Social-Emotional Intelligence, Holistic Well-Being

\section{Introduction}

The purpose of education is to successfully prepare students for the future, and therefore we cannot continue educating them in ways that address education and market needs of the past. The world has changed exponentially in ways that are not always easy to understand, so as to accurately predict and prepare students for the future. Thus, a new trajectory in education is urgently needed. Today, an authentic, unbound, and exciting educational paradigm is needed to educate students for complex and ambiguous future needs. In particularly, primary grades, need to design an environment of engagement with creativity and innovation which should be the norm and not the exception.

Therefore, all institutions of the world must inspire their students to develop the wisdom to transform their educational experience into social, economic, environmental, intellectual and ethical resources to improve their lives, but most importantly the lives of less privileged students across the globe. Academic institutions, now more than ever, have to provide educational opportunities and experiences which are determined by their culture defined through “...its' history, policies, management style and most importantly the thinking and behavior of it's constituents." (Pelonis and Gialamas, 2010)

ACS Athens has a culture of developing and implementing innovative programs while adopting an authentic leadership approach to transform student's lives. As a result, ACS Athens, after almost a decade of research, planning and classroom application has developed and is implementing an authentic educational approach called the Global Morfosis Paradigm. This dynamic Paradigm consists of three inseparable, interconnected, and interrelated components: 1) the Morfosis, from the Greek word Mó $\varphi \omega \sigma \eta$ (ethical, intellectual and social shaping of the human character), 2) Educational Philosophy, the $\mathrm{I}^{2}$ Flex (i square Flex), Delivery Methodology,

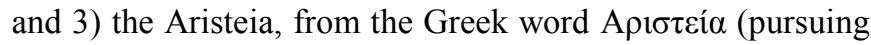
excellence under the guidance of ethos) Leadership Trajectory. Following is a brief review of the Global Morfosis Paradigm.

\section{The Global Morfosis Paradigm}

In brief, the Morfosis Educational Philosophy is defined within the $21^{\text {st }}$ century framework, as a holistic, meaningful and harmonious educational experience guided by ethos. The 
vehicle to implement this paradigm is the $i^{2}$ Flex (read: $i$ squareFlex), a non-traditional learning methodology, organically developed by the ACS Athens community of learners. It is supported and supplemented by Aristeia Leadership, an innovative leadership approach guided by ethical discipline, which refers to the continuous act of effectively engaging all members of the institution (constituencies) while utilizing their differences, energies, inputs and diverse qualities primarily for the benefit of the students, and also for all constituencies of the institution (Avgerinou, 2014).

\subsection{The Morfosis Educational Philosophy}

It is Holistic for successfully combining the academic, emotional, physical, intellectual and ethical components to ensure a healthy and balanced individual. It is Meaningful for it is in line with the learner's principles and values as well as with his/her personal goals. That is, the educational experience must be meaningful for the learner who should see it as an intrinsic part of his/her life and not in isolation. In addition it must be meaningful in relation to his/her dreams, strengths, desires and talents. It isHarmonious in that it refers to the idea that all human aspects must be in harmony. In other words emotions, intelligence and intellect must be harmoniously integrated with the learner at the forefront (Averginou, 2013). Finally, this educational approach is operating within the framework of Ethos which is"...doing the right thing, even when no one is watching."(C.S. Lewis, $20^{\text {th }}$ Century Author).

\subsection{The I' Flex Delivery Methodology}

Drawing on the research and practice of blended learning, $i^{2}$ Flex integrates independent student learning and inspiring learning guided by a faculty mentor and the face-to-face learning that is flexible in terms of pace, time, place, and/or mode of delivery. Given that much of the world of knowledge acquisition associated with the intellectual process of remembering, understanding and application can be accomplished through online learning activities as well as independent investigation. Students using this methodology are engaged in learning opportunities that exist in many forms, and thus learning occurs anywhere, anytime (Averginou, Gialamas \& Tsoukia, currently in print).

\subsection{The Aristeia Leadership Trajectory}

This innovative approach is defined by two essential components: the establishment of an Authentic Leadership Identity (ALI) and the creation of a Collective Leadership-Partnership Approach (CPA).

The first component can be expressed by the Socratic philosophy of living a life of meaning begins with the quest to "know oneself". That is, the process of understanding where we come from and how life has affected and shaped our personalities, life choices and approaches to living is important in developing and defining a leadership identity. Therefore "knowing oneself" is a necessary first step in creating the leadership vision and defining its philosophy of education (Gialamas \& Pelonis, 2009).

The second component is based on defining the professional goals through a process of self-reflection and revision. The questions a leader must continue to ask in order to revise and refine his/her leadership approach are: where do we want life to take us, and how can we participate in this co-creative process? Moreover, partnerships and collaborations ensure that there are checks and balances, that other individuals participate in the decision making process and that there is a comprehensive support system in place to ensure that the institution thrives and functions at the highest possible level of achievement. In addition it is crucial that all members of the leadership partnership share a belief in the institutional vision and are committed to striving towards reaching common goals (Gialamas \& Pelonis, 2009).

Finally, it should be noted that recent research confirms the validity of the previously described holistic paradigm. Koutsopoulos (2014) suggested that nowadays in education"a need exists for an integrated approach which is simultaneously pedagogic (i.e. new role of teachers), methodological (i.e. non-traditional learning methodologies), technical/ technological (i.e. use of the internet), administrative (i.e. new role of school administrators), social (i.e. a different disposition of parents towards school), political (i.e. a different approach of government to school) and cultural (i.e. new role of students), in dialectic harmony and respecting all aspects of teaching and learning an integral part consisting of pupils, teachers and school administrators."

\section{Dogs in Learning (DiL):/Literature Review}

Echoing such an integrating Educational Paradigm and based on the ever present desire of the ACS Athens leadership to utilize the Global Morfosis Educational Paradigm, a new educational approach has been developed (K-5) and applied by a team headed by Theo Koutsopoulos, one of the school's faculty members. Dogs in Learning(DiL)is designed to use highly trained dogs as an inspirational vehicle to help children understand and apply everyday issues related to human behavior such as: leadership, non-violence, patience, respect, kindness, empathy love, team work, responsibility, confidence, friendship, trust etc. In addition a plethora of curriculum contents at the Elementary School are being taught and learned by students in a meaningful and fun way.

The effect that school has on children's development allows us to examine critically, creatively and sensitively, the environmental factors that contribute to children's positive adjustment to school (Baker, Dilly, Auperlee \& Patil, 2003). Schools are important contexts for children's development as the time spent in school influences their experiences (life and learning), self-perceptions and how one's life progresses (Baker, Dilly, Auperlee \& Patil, 2003). Children who develop positively have several specific characteristics in common: a) sufficient personal assets and competencies and b) 
effective nurturance and support from the social environment. It is these resources that protect the children from stress and dysfunction (Luthar, Cicchetti \& Becker, 2000).

It is essential to examine the number of ways in which positive adaptation has been conceptualized in the school setting. Some of these ways include: a) the school climate (Epstein \& McPartland, 1976), b) classroom structures, goals and practices (Ames, 1992; Eccles et al., 1998), c) school organization and structure (Baker et al., 2001), d) student demographics, e) student academic ability, f) student mental health, family relations and g) peer relations (Doll, 1996). School practices that foster positive adjustment or holistic health (social, emotional, physical and cognitive balance): 1) enhance children's meaningful connections to others in the school environment, 2) enhance children's sense of competence as learners and 3) promote a sense of autonomy and self-direction that are associated with positive school attitudes and overall healthy functioning both in school and society (Baker, Dilly, Auperlee \& Patil, 2003).

Greenberg et al. (2003) also suggested that children who are socially and emotionally competent tend to be more happy, confident and equipped with strong interpersonal skills across various contexts and roles. Thus, supporting the importance of social and emotional learning as an intrinsic aspect of children's academic learning and performance, motivation to achieve and overall holistic well-being.

Social-emotional learning engulfs the process of developing fundamental social and emotional competencies or skills (Zins \& Elias, 2006). These skills enable children to manage their emotions, experience empathy, develop positive relationships, make good decisions, conduct their behavior ethically and responsibly (Collabortive for Academic, Social and Emotional Learning, 2003).

Research on the interaction between humans and animals not only posits the social, emotional and behavioral benefits but the physical ones as well. Increased contact with animals not only fosters nurturing behavior in children, increase social skills but also reduces physiological aspects of children's health, such as lower blood pressure, reduced allergies and increased relaxation (McCardle, et al., 2010;Vidovic, Stetic, \& Bratko, 1999).

Moreover, after WWII the utilization of dogs as a vehicle to attend to or resolve various issues arose and addressed the problems and needs of returning soldiers and has evolved greatly since then. Recent research indicates that interaction with dogs can temporarily affect the release of various neurotransmitters in the brain. Among the most important, it increases the levels of oxytocin (linked with bonding) and dopamine (involved in the reward-motivation system) and decreases the cortical levels (an immunosuppressant associated with stress) (Odendal and Meintjes, 2003). These results scientifically support the need and feasibility of utilizing/interacting with dogs as well as substantiate the fact that such interactions can incorporate a wide range of potential activities, with a wide range of potential groups of people.

The last point clearly indicates that the various programs of dog utilization are not uniform, but they are differentiated according to the goal of the interaction. Indeed research and experience indicate that up to now there have been three categories of utilizing dogs:

- Therapy Dog: The term is used to describe when a dog is trained to provide affection and comfort to people in various institutions as well as disaster areas and can be used in Animal-Assisted Therapy (to achieve a specific goal) as well as in Animal-Assisted Activities (to provide a more open ended, spontaneous interaction)

- Assistance/Service Dog: In this category a dog is trained to perform specific tasks to aid or assist a person with a disability

- Working Dog: Includes search and rescue dogs, military dogs, police dogs, detection dogs, guard dogs, hunting dogs, sled dogs, livestock dogs, classroom dogs etc.

However, as we are well into the $21^{\text {st }}$ century, important differentiations have occurred related to the way we view the dog-human interaction. There is a new category of dogs whose value and necessity are beyond the above mentioned categories. In essence, there is a need for a classroom dog that is capable of being an inspirational vehicle in learning, to assist children in applying the basics of human behavior (i.e. empathy, pro-social, ethical, etc). In other words, transform learning at ACS Athens by manifesting the Global Morfosis Paradigm utilizing dogs.

\subsection{The "Dogs in Learning" (DiL) Program}

The DiL program represents a new approach based on the last category, namely of dogs addressing issues of psychology and behavioral norms by correlating dogs' actions with human behavior. More specifically, the program leaders are Theo Koutsopoulos (an ACS Athens faculty member and a certified dog educator who has had over 20 years of experience in successfully training dogs and their owners and is the first dog trainer to introduce the concept of Animal Behavior and Behavior Modification in Greece)and Christina Birbil (a first grade ACS Athens faculty member, working with children of the Elementary School of ACS Athens with the beloved three-legged dog Captain Chip. Christina Birbil rescued this amazing three-legged puppy from what would have been a short and painful life on the streets.

The goals of the program embedded within the ACS Athens (K-5) School Curriculum are simple and forward. Namely, to link empathy as well as social and emotional learning within an academic context that highlights behavioral concepts, facilitates learning as well as instills Z $\omega \circ \varphi \imath \lambda_{\imath} \alpha$ - a love for animals as sentient beings. ACS Athens dogs are primarily used in the Elementary School, however, they are available to participate in learning across campus. The program is based on the following principles.

\subsubsection{Resilience}

This basic principle refers to a holistic approach to education, which is physical, cognitive, social and emotional. Thus, also exemplifying an individual's ability to adjust and adapt to adversity and major changes in life. 


\subsubsection{Empathy}

Dog behavior and treatment of the dog promotes this principle by:

- Caring about others and having a desire to help them

- Discerning what another person is thinking or feeling

- Understanding and connecting to the emotions of another

- Nurturing relationships

- Bringing out the best of human behavior; feelings and emotions

\subsubsection{Emotional Intelligence and Social-Emotional} Learning

This principle promotes positive thinking through a series of actions and activities such as:

- Coordinating thoughts and actions

- Enhancing critical thinking skills

- Encouraging responsible and ethical decisions

- Promoting healthy pro-social behavior

- Building character - enhancing academic achievement

- Building self-esteem

- Encouraging role-play

- Opportunities for fun educational activities

\subsubsection{Promoting “Human and Dogs Bonding”}

This principle determines the interaction with the dogs, in order to achieve:

- Responsible pet ownership

- Caring for the class dog (provide: food, water, grooming, walking, playing and training)

- Promoting multi dimensional, positive hands-on experiences with dogs

\subsection{Spiral Curriculum Approach}

The DiL program is a well designed educational program based on a spiral curriculum repeating five key elements within, and implementing the ACS Athens (K-5) curriculum through the use and engagement of dogs.

The Spiral Curriculum is an old and well-known approach suggested by Bruner (1960), who claimed that "We begin with the hypothesis that any subject can be taught in some intellectually honest form to any child at any stage of development". Bruner's followers accept that even the most complex material, if properly structured and presented, can be understood by very young children.

As a result, the basic features of the spiral curriculum are:

- The student revisits a topic, theme or subject several times throughout their school career.

- The complexity of the topic or theme increases with each revisit.

- New learning has a relationship with old learning and is put in context with the old information.

Which in turn provide the following benefits:

- The information is reinforced and solidified each time the student revisits the subject matter.

- The spiral curriculum allows for a logical progression from simplistic ideas to increasingly complex ideas.

- Students are encouraged to apply their previous knowledge to later course objectives.

It is the simplicity of the approach and the benefits it provides that tipped the scale in deciding to use this curriculum approach in the DiL program. However, DiL operates within the school's teaching philosophy and follows ACS Athens' (K-5) curriculum.

The key elements and their spiral position in the ACS Athens (K-5) curriculum are:

- $1^{\text {st }}$ Grade: PATIENCE

- $2^{\text {nd }}$ Grade: PATIENCE-CONFIDENCE

- $3^{\text {rd }}$ Grade: PATIENCE-CONFIDENCE-FOCUS

- $4^{\text {th }}$ Grade: PATIENCE-CONFIDENCE-FOCUS-TEAM WORK

- $5^{\text {th }}$ Grade: PATIENCE-CONFIDENCE-FOCUS-TEAM WORK-LEADERSHIP

By working with dogs at ACS Athens, students are taught a new element every year while repeating the elements of previous years in a more advanced manner, which illustrates depth of knowledge. It should be noted that in the educational spiral approach the operating principle is that a child at any stage during his/her development can be taught any of the above elements. As a result, the program can start at any grade level.

\subsection{The Dogs at ACS Athens (ACS Athens Dogs)}

The ACS Athens Dogs used in the Elementary School classrooms have undergone in-depth positive reinforcement training and thus they have been rigorously assessed to be competent and safe to work within the school environment.

The ACS Athens Dogs can have many positive benefits, achieving various tasks. They can perform a series of objectives from simple to more substantive, the latter being the major contributing factor of the program. More specifically they can be:

\subsubsection{Classroom Participants}

ACS Athens Dogs can simply be present in the classroom whilst the children are having their lesson(s). As a result, their very presence has a calming effect on the children.

\subsubsection{Listening Audience}

By being incredibly calm, ACS Athens Dogs are happy to have an individual child read to them or join a group of children while having a book reading session. As a result these dogs:

- Improve reading levels as the child practices the skill of reading (especially in emerging readers)

- Increase positive self-esteem as the $\operatorname{dog}$ is a non-judgmental, attentive listener

- Motivate child to read, as reading is now associated with something fun

- Facilitate conversation and socialization amongst the children they interact with

\subsubsection{Reward Providers}

Working and playing with a dog improves children's social skills and self-esteem. Moreover, considering that ACS Athens Dogs are gentle, loving and approachable, their very 
presence is a rewarding. Children at ACS Athens spend time undertaking certain responsibilities for their classroom dog, which include: providing food and water, walking, grooming, playing and training. These opportunities enable students to build their self-esteem by feeling needed and responsible for the benefit of another and these experiences also encourage pro-social behaviors while working within a group.

\subsubsection{Educational Facilitators}

ACS Athens Dogs have shown that they can facilitate learning concepts for literacy and language development, mathematics, biology, social studies etc. Faculty members have embraced this curriculum and have enhanced the existing curriculum by providing learning activities which include the dogs.

\subsubsection{Social Facilitators}

ACS Athens Dogs bring much joy and help to all the children they meet and are happy to provide plenty of attention and affection to children who are spending time with them. The classroom dog provides some comic relief during anxious times, as well as acts as a friendly ice-breaker, since their very presence diverts attention from the individual to the dog, thus encouraging pro-social skills and dialogue. In other words, children who struggle with social interaction find a reassuring friend in an ACS Athens Dog.

\subsubsection{Psychological Support}

ASC Athens dogs work with children on a one-to-one basis, thus helping children who may be going through upsetting/difficult times or have been scared/phobic of dogs. In addition they helps students with low self-esteem improve their self-image as well as enable introverted students to take more risks. Finally, ACS Athens dogs help to improve morale, concentration, anxiety and hyperactivity.

\subsubsection{Empathy Providers}

ACS Athens Dogs encourage a broad range of emotional/feeling states in children, including caring for other people and having a desire to help them; experiencing emotions that mirror another person's emotions; discerning what another person is thinking or feeling; and making less distinct the differences between themselves and others. In other words, by identifying and relating to the classroom dog, they intrinsically learn to apply and manage their emotions in the way they treat other people.

\subsection{DiL Program Implementation}

The ACS Athens DiL program was initiated and applied over the last two academic school years (2012-13 and 2013-14), in three grades of the school $\left(1^{\text {st }}, 2^{\text {nd }}\right.$ and $\left.5^{\text {th }}\right)$. Due to its success, starting this year (2014-15), a full implementation of the program has begun in the homerooms of all grade levels in the Elementary School. The program coordinators are: dog educator Theo Koutsopoulos, first grade teacher Christina Birbil and their assistant Xenia Vafopoulou. The ACS Athens Dogs are: Captain Chip in $1^{\text {st }}$ grade, Iro in $2^{\text {nd }}$ grade, Xanvier in $3^{\text {rd }}$ grade, Talos in $4^{\text {th }}$ grade, Aika in $5^{\text {th }}$ grade and Arno throughout the grade levels.

\subsubsection{Overall Objectives and Goals}

During the initial pilot period and via Captain Chip (the first dog of the program), $1^{\text {st }}$ graders and later $2^{\text {nd }}$ and $5^{\text {th }}$ graders, had an enriched program which provided them with innovative educational methodologies, both inspiring and empowering children psychologically, socially, emotionally as well as academically. The ACS Athens Dogs, in addition to working with Elementary School students, have also participated in K-12, citizenship activities. More specifically:

Psychologically: Children at ACS Athens, who are growing up in a society where animal neglect is prevalent, become empowered to make a difference and not turn a blind eye. In addition, they instill passion in what they do through compassion. Enabling students to care for work with and train a dog, helps them to realize that every action has a consequence regardless of who they are or how old they are. This opportunity has the power to change the way they feel about themselves and others, while allowing them to continue to develop compassion, empathy and respect.

Socially: By socializing and training dogs, children at ACS Athens are educating themselves on how to incorporate the dogs into their daily lives through a solid basis of respect. Finally, students learn the basics of animal handling, which include:

- How to properly approach and meet a dog

- Overcome dog phobias (if any)

- Basic training commands (come, heel, sit, sit-stay and down-stay)

- Responsible pet ownership, including walking, feeding, grooming and playing with a dog

- Understanding dog behavior

Emotionally: Children across grade levels have the opportunity to have meaningful moments to bond with the ACS Athens Dogs. That is, throughout the day students' self esteem is solidified as they are interacting with and seeing their dog respond to their requests, thus providing a tangible experience in leadership as well as empowering students to become accountable decision makers in all areas of life.

Academically: The program is integrated into the academic curriculum of the school, differing from the rest of the educational activities in that it utilizes the expertise of faculty who have professional dog training and behavior experience as well as the use of a hand-picked team of dogs to enrich and enhance student learning in a variety of subject areas, using different approaches. For example, the Elementary School children of ACS Athens have been inspired, during the pilot stage, to write letters to Captain Chip as well as read aloud to him on a daily basis (both activities continue to maintain fan club status) and thus inspire children to be more communicative, compassionate and involved. The act of reading aloud to a non-biased listener enables them to feel safe as well as take risks. In addition, the presence of dogs in the classrooms not only facilitates the teaching of reading and writing but also facilitates the teaching of mathematics, biology, social studies etc. 
It should be noted that the overall objectives and goals of the now expanded program are essentially those achieved during the pilot period, improved and refined to reflect the experience gained during that time period.

\subsubsection{Objectives and Goals by Grade Level}

The overall goals of the program, following the spiral curriculum, have been individualized for each grade to fit the needs and abilities of its students. Therefore, in each grade level, accomplishing the identified objectives and goals enables students to better correlate academic learning outcomes with this program hands-on way.

\section{(i) First Grade}

The objective in the $1^{\text {st }}$ grade is to meet and greet dogs as well as train them to obey basic commands using treats. ACS Athens faculty members work with students teaching them about dogs and how to handle them (what to do, what not to do and why). In doing so the students are taught about the meaning and importance of patience. By training a dog to focus, the goal is for children, to work with PATIENCE.

To accomplish these objectives and goals, student shave to work closely with all faculty involved (their teacher, the homeroom team and a faculty-certified dog trainer). The faculty is teaching children to bond with their dog through socializing with and caring for their dog. Training their ACS Athens Dog, Captain Chip, in basic commands helps educate children on how to incorporate Captain Chip into their daily lives through a solid basis of respect. Captain Chip is a three-legged dog, and as such, required an adjusted approach in training and handling. The faculty involved have motivated children to be patient while handling Captain Chip.

Academic correlation: $1^{\text {st }}$ graders are inspired to develop reading skills, written communication skills, conversational skills all within relation to Captain Chip, thus increasing their vocabulary and ultimately their sense of self and self worth within a group. All of the above make learning fun, encourage risk-taking and increase happiness.

\section{(ii) Second Grade}

The objective in the $2^{\text {nd }}$ grade is to transfer from treat-oriented dog training to 'the promise' of a treat. This means that the class dog is responding to students' requests based on the child and not the treat. The dog learns to respect the command requested because of pack leadership, so children must exhibit confidence in order to attain the dog's attention. As a result, the key connection made in this grade level is equating dog behavior with how children behave towards others and why. The goal is to have children work with CONFIDENCE. Students are taught that it is important to be confident about what he/she is doing when working with a dog so that the dog feels secure next to him/her.

To accomplish these objectives and goals, students learn how to bond and communicate with their dog throughout the day. As a result, as they see the dog responding to their requests, their self-esteem is firmly established. This also provides them with the tangible experience of Confidence.

Academic correlation: $2^{\text {nd }}$ graders have the opportunity to interrelate subjects hands-on. For example, in mathematics, in a playful way, students practice to count the number of steps they have to make forwards or backwards in a certain area to allow the dog to perform an exercise. Additionally, they are asked to count the time needed in order for the dog to complete the required task and then reward it. This process provides them with the opportunity to solve meaningful, real world mathematical problems.

\section{(iii) Third Grade}

The objective in the $3^{\text {rd }}$ grade is to teach students how to concentrate their efforts when handling an energetic dog. More specifically, focus is built in the classroom through their interactions with the specific dog. By requiring students to combine focus on the dog within a time limit, they realize that the moment they themselves lose focus they immediately lose the focus of their dog. Of course as the class progresses, the time limit is shortened, thus forcing students to be more alert.

The goal in this grade is to have students work with FOCUS. By concentrating their efforts and directing their attention toward a specific outcome, children will achieve their desired result in the dog.

Academic correlation: $3^{\text {rd }}$ graders have opportunities to integrate academic subjects which revolve around their ACS Athens Dog. For example, they contribute in class and small group discussion about their dog; moreover students are asked to count the number of times an exercise is performed by the dog in order to follow its progress and express mathematical relationships by observing how many times a dog needs to repeat an exercise until it feels confident. Therefore, they collect, organize, classify data and reflect on it to draw a conclusion.

\section{(iv) Fourth Grade}

The objective in the $4^{\text {th }}$ grade isto ask students to participate in exercises with a dog that needs team cooperation to be completed. In addition, while the task remains the same, the role of every team member changes so they can appreciate the importance that all have to contribute towards the final objective.

The goal in this grade is to teach students the principle of TEAMWORK. That is, the work that needs to be done is accomplished when each member is on task doing their part with the consistency of the final outcome remaining the same. TEAMWORK requires the goals from the previous grades of PATIENCE, CONFIDENCE and FOCUS.

Academic correlation: Given the focus of this grade, a typical academic exercise is for students to be able to work in a team where each member has a different assigned responsibility when working with the dog in an obstacle course. That is, students learn to solve measurement problems using different units; one student can keep record of the time needed for the dog to overcome the specific obstacle or the entire course; another, to measure the height the dog needs to jump; another, the distance covered by the dog, etc.

\section{(v) Fifth Grade}

The objectives of the $5^{\text {th }}$ grade are based on the 
psychological theory of the human-animal bond and pack dynamics. It is a unique, kind method in which the dog elects the student as his leader of his own free-will. In addition, the roles for each team member are decided by the students themselves (as opposed to the $4^{\text {th }}$ grade being assigned given roles). By deciding themselves what they will do, students gain hands on, meaningful experiences in exercising LEADERSHIP.

The goal is for students to understand and appreciate how much their relationship with the dog improves if the dog actually wants to cooperate of its own free-will and not by force. This bond happens when the dog recognizes a patient, confident and focused individual. By gaining experience in the theory behind the psychology of the human-animal bond and pack dynamics, students learn to handle their behavior appropriately and appreciate the meaning of LEADERSHIP.

To accomplish these objectives and goals the students are deepening their learning about dogs, the pack and how to handle a dog in various circumstances. That is, students can be taught leadership through dogs because key factors of their own character, their instinct and their importance, determine how powerful a dog is and how its reactions are directly correlated with our own actions.

In order to illustrate pack leadership in action, students need to be able to distinguish the difference between being a leader (calm) and being a bully (bossy). A typical exercise used towards that objective is for the faculty to use an ACS Athens Dog to show students the importance of the true leader and the bully as follows:

One person holds the dog and the faculty approaches him/her in three different ways:

$1^{\text {st }}$ way: The faculty approaches the dog reluctantly with slow moves, not confident about himself/herself and indicating that he/she is a little scared. The reaction of the dog is that he/she becomes suspicious of his/her owner and looks at him/her with mistrust.

$2^{\text {nd }}$ way: The faculty approaches the dog with confidence, walking towards him/her normally and calmly, as well as petting him/her. The dog's reaction is to wag his/her tail and enjoy the owner's affection.

$3^{\text {rd }}$ way: The faculty approaches the dog walking with big steps, emitting to the dog an aggressive body language. The dog's reaction is to step back and lean on the person holding him/her. As a result, it becomes fearful and immediately lies down, showing a total submission to the owner without understanding the reason of his/her attitude.

By witnessing the above reactions to leadership and bullying behavior in their ACS Athens dog, students can gain a clear picture of what a positive leader looks like and what their actions instill on others, as opposed to bullying and how their actions can impact those around them. This and other examples teach students the importance of true leadership and the correlation to the anti-bullying theory.

Academic correlation: $5^{\text {th }}$ graders, in addition to being inspired by the five key elements at an advanced level, are given the opportunity to work in a series of academic subjects. For example, by measuring the speed of two dogs having different heights, students can correlate the length of a dog's leg with his running ability.

Overall, using various dog training techniques, the faculty teaches the children all five key elements in the spiral curriculum approach: Patience, Confidence, Focus, Teamwork and Leadership. Through the DiL program students have the opportunity to understand how they may lack confidence when they are working with a dog for the first time. By exercising patience and remaining calm, they have the opportunity to gain confidence in the field, thus learning to keep the dogs' focus and attention on them. In addition, they realize that in order to reach their goals they have to work as a team. Finally, by working and handling a dog in this way they become true leaders.

The techniques applied with all dogs in every classroom at ACS Athens Elementary School are uniform. ACS Athens Dogs are rewarded, depending on their task and what is needed to be accomplished, in three ways: with food, by petting them, or finally, by rewarding them with kind words.

\section{Initial Findings and Observations}

The initial findings of the pilot application of the DiL program have shown that the classroom dogs at ACS Athens can have many positive benefits, facilitating achievement in the following:

- Improves reading

- Overcomes the phobia of dogs

- Motivates those children who are often not that attentive

- Helps children keep calm

- Builds confidence

- Forms a bond among classmates and strengthens their team ethics

- Improves academic achievement

- Provides children with responsibility and encourages them to respect all life

- Provides happy, playful but constructive time

- Modifies Behavior

- Promotes Empathy

\section{Implementation of DiL Program}

In order for the DiL program to be implemented the following resources, support and infrastructure are required:

1) a dog educator responsible for training the faculty, 2) appropriate certified dog assistant educators to support faculty, 3) acquisition of classroom dogs for each grade, which requires their selection after evaluation as well as a series of preparatory tasks such as vaccinations, insurance etc., 4) a well written curriculum with clear goals and objectives, 5) a series of equipment such as an obstacle course and 6) administrative support.

\section{Conclusions}

In summary, the main contribution of the DiL program is 
that through the presence and use of dogs in the classroom, a manifestation of the Global Morfosis Paradigm is attained. More specifically, following a spiral educational curriculum using five key elements, some basic issues related to human behavior are internalized by the elementary school children at ACS Athens, which can further their understanding of, and appreciation of the emotional and feeling states of other people (i.e. kindness, empathy, joy, loss, sadness, anger Additionally, they are provided with opportunities to feel connected, safe and secure.

It should be noted that the five key elements of the DiL program can certainly be taught to elementary, middle and high school students, as well through other academic subjects, or by using different educational approaches. However, the position presented here is simple in its explanation, but radical when considered in terms of the current practices in education. That is, educational processes and the teaching of the basic key elements such as Patience, Confidence, Focus, Teamwork and Leadership cannot be addressed as successfully with traditional educational practices. In addition, curriculum subjects can be taught more effectively and in a playful and enjoyable manner when the learner is engaged in the learning process. Providing meaningful hands-on opportunities to children allows them to take their learning to a different level. In essence, these elements and other subjects can be successfully taught because animals, especially dogs, are capable of attracting and holding the attention of children and inspire students of all ages (a very difficult task in traditional educational approaches). The most representative example we face today is the anti-bulling phenomenon which, in our opinion, the DiL program successfully addresses in a hands on and meaningful manner, which is extremely effective, engaging and long-reaching. Most importantly, the DiL program represents the successful manifestations of a learning approach which is the dialectic entity of the Global Morfosis Paradigm.

The literature indicates that most members of the educational community, independent of national conditions, and level of education and educational role have accepted the need for a new paradigm where the holistic role and the advantages offered by Global Morfosis can provide the framework within which it has to develop (Koutsopoulos, 2013). As a result, the approach discussed in this paper, Dogs in Learning is a successful manifestation of that paradigm and an innovative response of ACS Athens to the present day's educational needs. Indeed, DiL can be applied in any school by using properly trained dogs in the classroom, thus allowing faculty and students to engage in educational themes (key elements) where conventional teaching approaches have lacked addressing effectively, and they can do so in an innovative, playful and effective way.

Therefore, the DiL program is inspiring students to develop the wisdom to transform their educational experience. In addition, the DiL program, in its infancy, proves that young learners can be inspired to reach their maximum capacity ethically, emotionally, socially, physically, intellectually and academically. We need the next generations of leaders to lead with ethos, kindness and mindfulness; basic tenants of the Morphosis paradigm, in order to establish a better world in which to live for all (Gialamas, 2014).

\section{Recommendations for Future Research}

As the DiL program continues to develop, progress and fine tune all of its' essential delivery components, advances in research can be carried out at ACS Athens, or in any other institution with similar programs for that matter. In the Elementary School at ACS Athens, students' attitudes and feelings about the DiL program will be explored in the upper grade levels, ( $4^{\text {th }}$ and $5^{\text {th }}$ grades). These two grades, not only provide for a valid sample population at minimum of a 100 students, but older students are also more developmentally ready to respond to questions pertaining to the described program. Students will be given a survey based on a Likert-type scale, which will consist of a number of questions related to their experiences (attitudes and feelings) as learners and participants of the DiL program. The responses to the questions are scaled on degrees of agreeableness. The surveys will be collected; the data coded and results statistically analyzed by the appropriate faculty members.

\section{References}

[1] Ames, C. (1992). Classrooms: Goals structures and student motivation. Journal of Educational Psychology, 84, 267-27.

[2] Avgerinou, M.D. (2014, March 19).i2Flex. The New York Times International\&Kathimerini. Available online at http://www.ekathimerini.com/4dcgi/_w_articles_wsite6_1_19/ 03/2014_538303

[3] Avgerinou, M.D. (2013, Winter). Digital natives, disruptive schooling and other brainteasers. Ethos, 8-11.

[4] Avgerinou, M.D., Gialamas, S., \&Tsoukia, L. (in print). i2Flex: The meeting point of web-based education and innovative leadership in a K-12 international school setting. In D.G. Sampson, D. Ifenthaler, J.M., Spector, P. Isaias, P. (Eds.). Digital systems for open access to formal and informal learning. New York: Springer.

[5] Baker, J.A., Dilly, J. (2003). The Developmental Context of School Satisfaction: Schools as Psychologically Healthy Environments. School Psychology Quarterly, 18, 206-221.

[6] Baker, J.A., Derrer, R., Davis, S., Dinklage-Travis, H., Linder, D., \& Nicholson, M. (2001). The flip side of the coin: Understanding the school's contribution to drop-out. School Psychology Quarterly, 16, 406-427.

[7] Bruner, J. (1960). The Process of Education. Cambridge, MA: The President and Fellows of Harvard College.

[8] Collaborative for Academic, Social and Emotional Learning. (2013). Safe and Sound: An educational leader's guide to evidence-based social and emotional learning programs. Chicago: Author.

[9] Doll, B. (1996). Children without friends: Implications for practice and policy. School Psychology Review, 25, 165-183. 
[10] Epstein, J.L., \& McPartland, J.M. (1976). The concept and measurement of the quality of school life. American Educational Research Journal, 13, 15-30.

[11] Fullan M., and Langworthy, M., 2013.Towards a New End: New Pedagogies for Deep Learning, http://www.newpedagogies.info/wp-content/uploads/2014/01/ New_Pedagogies_for_Deep Learning_Whitepaper.pdf.

[12] Gialamas, S. (2014, May 8).Educational institutions for a more humanistic world.The New York Times International \&Kathimerini.Available online at http://www.ekathimerini.com/4dcgi/_w_articles_wsite6_1_08/ 05/2014 539551 .

[13] Gialamas, S. (2011, October 13). Leadership collaboration: High school and college environments. International Herald Tribune. Available at http://www.acs.gr/publications/2011/10/13/leadership-collabor ation-high-school-and-college-environment.html.

[14] Gialamas, S., \&Pelonis, P. (2009). Morphosis leadership being visionaries in a changing world.Academic Leadership Online, $7(2)$. Available http://www.academicleadership.org/327/morphosis-leadership being-visionaries-in-a-changing-world/.

[15] Greenberg, M.T., Weissberg, R.P., O’Brien, M.U., Zins, J.E., Fredericks, L., Resnik, H., \& Elias, M.J. (2003). Enhancing school-based prevention and youth development through coordinated social, emotional and academic learning. American Psychologist, 58, 466-474.
[16] Koutsopoulos, C. K. (2013).School on cloud: towards a new paradigm. Themes in Science and Technology Education, 1, (1), $47-62$.

[17] Koutsopoulos, C. K. (2011).Changing Paradigms in Geography. The European Journal of Geography, 2, (2), 54-75.

[18] Luthar, S.S., Cicchetti, D., \& Becker, B. (2000). The construct of resilience: A critical evaluation and guidelines for future work. Child Development, 71, 543-562.

[19] McCardle, P., et al. (2010). Animals in our lives. Human-Animal Interaction in Family, Community, \& Therapeutic Settings. Pacific Grove, CA: Brooks Cole.

[20] Odendaal, J. S., and Meintjes, R. A.(2003). Neurophysiological Correlates of Affiliate Behavior between Humans and Dogs. The Veterinary Journal,6, 15-23.

[21] Pelonis, P., \& Gialamas, S. (2010). An international perspective of academic leadership. International Schools Journal, XXX (1),72-85.

[22] Zins, J.E., \& Ekias, M.J. (2006). Social and Emotional Learning. In G. bear \& K.Minke (Eds.) Children's needs III. Bethesda, MD: National Association of School Psychologists. 